\title{
Review of lightning protection standard in building structures in Nigeria.
}

\author{
${ }^{1}$ A. U. Adoghe, ${ }^{2}$ A. F. Agbetuyi, ${ }^{3}$ A. Abdulkareem ${ }^{4}$ J. O. Olowoleni and \\ ${ }^{5}$ C. O. A. Awosope \\ 1, 2, 3, 4,5 Department of Electrical and Information Engineering, School of Engineering, Covenant University, \\ Ota, Nigeria
}

\begin{abstract}
A lightning protection system performs a simple task. It provides a specified path on which lightning can travel. When a building structure is equiped with a lightning protection system, the distructive power of the lightning strike is directed safely into the ground, leaving structures and equipment unharmed. This paper provides a comprehensive guidance for selection and installation of protection devices for building structures.
\end{abstract}

Key words: Lightning protection, building structures, system performance, lightning strike and Surge suppression

\section{Introduction:}

A properly installed lightning protection system performs the simple, yet invaluable task of providing a network of low resistance paths for lightning current to follow in preference to other parts of a structure. While the concept behind lightning protection is relatively simple, the requirements for proper installation are specific and often complex. The single best way to ensure proper lightning design and installation is to make sure that the design details agree with the nationally recognized safety standards for lightning protection, maintained by the National Fire Protection Association (NFPA 780) and Underwriters Laboratories (UL96A). Strict compliance with the requirements of these standards is essential for proper system performance. It is true with any safety system, ensuring correct installation the first time is a must, since waiting for nature to send down a bolt of lightning to test the system's quality can have catastrophic results [1].

A lightning protection system that complies with national standards must include all the following elements: a) a network of roof-top air terminals, b) a network of ground terminations, c) a network of conductors interconnecting the air terminals and grounds, d) interconnections with metallic bodies, and e) surge suppression devices on all incoming power and communication lines. The first three elements serve to intercept, conduct and dissipate the main lightning discharge. The fourth element addresses the secondary effects of a lightning strike by limiting the dangers of the harmful current jumping or side flashing within a structure. The last element protects power lines and connected equipment from damaging currents traveling on utility lines. Each of these elements is essential to proper system performance. Failure to make proper provisions for any of these five elements can result in inadequate protection. The primary focus of this paper is to outline the requirements for providing lightning induced event protection to facilities as well as the personnel within or near these facilities. Specify some of the internationally accepted standards and design guides identify the quantifying risks, state some of the control measures and critically examine what is practised in real world in most building structures in Nigeria. The paper is organised as follows. In section II, the fundamental of lightning phenomena relevant to this paper are summarised. The standards and design guides are addressed in section III, including quantifying risks. Control measures that relate lightning protection are discussed in section IV. Section V discusses the real world protection design as applied to building structures in Covenant University in Nigeria.

\section{Fundamentals of Lightning Phenomena}

How charges build up in the cloud is not well understood but the separation of charges in the cloud is the source of lightning [2].The build up and separation continues until the voltage difference between the cloud and the ground exceeds the air insulation strength, this resulted in a lightning discharge as the air resistance is overcome. Building and structure protection is an essential part of any overall lightning protection system. One of the key components of any system is the type of "air terminal" placed on the structure. The primary purpose of an air terminal is to capture the lightning stroke at a preferred point, so that the discharge current can be directed into the down conductor for connection to the earth system. A protection system, where the air terminals fail to capture the lightning flashes, will lead to loss of both protected structure /equipment and waste of money. Two important aspects that must be considered are the: (a) the protection area covered by each air 
terminals, and (b) the location of the air terminals on the structure. These two must be accounted for in any lightning protection design method that is adopted.

\section{Design specification guidelines and Risk assessment needs of a typical building} Structure.

The practical application guides to protect building structure against lightning and its effect are essentials, as there are no devices able to change the natural weather phenomena in order to stop lightning discharges. Lightning striking a structure, directly or nearly, can be risky to people, buildings and their contents. The basic principle in the protection of this life and property against lightning is the provision arrangement by which lightning discharge can enter or exit earth with no harmful effect to structure and their contents. Therefore, this section addresses the guideline standards to be adhered to, for providing protection to facilities as well as personnel within or near these facilities from the consequences of lightning induced effect.

Standard for the installation of lightning protection systems remains as the basic requirement for specifying lightning protection. Moreover, development of existing lightning protection standards in the United States of America (U.S) as well as other parts of the world is based on the same scientific sources.

Protection from lighting - induced hazards can best be achieved by a properly designed and installed lightning protection system in accordance with the requirements of National Fire protection Association (NFPA 780) [1]. The minimum design requirements for lightning protective system are (a) the use of strike termination device (b) low impendence paths to ground (c) an earth electrode system (d) bonding of all conductive penetrations and equipment into the protected area (e) surge suppression (f) side flash protection. In addition, the location, type of construction or the use to which these structures are put are also important as lightning strike can have particular serious consequence on both the equipment and the structure itself.

3.1 Requirement for components of strike termination system: The main component for lightning protection system used to intercept lighting strikes is an air terminal. Air terminals include vertical spikes attached to the structure, overhead wires etc. The air terminal shall be certified by underwriter's laboratory (UL 96) and shall comply with NFPA 780 standard as follows:

- Appropriate air termination method

- Air terminals shall be in the vertical position

- No high resistance joints at air terminal base

- Inclusion of natural components like down-conductor and earthing for air terminal

3.2 Low impedance path specification Conductors shall provide low impedance paths from air terminals to the earth electrode system and shall comply with the requirements of NFPA 780. The standard shall describe dimensions and tolerance for metal conductors as well as the test requirements to the electrical and mechanical (Tensile strength) values of the material. The resistance of lightning grounding system shall not exceed $25 \Omega$ unless approved by the Authority Having Jurisdiction (AHJ). However, a lower resistance than $25 \Omega$ is preferred [2].

3.3 Requirement for an earth electrode system. Lightning protective systems require an earth electrode (ground) system to dissipate the electrical energy of lightning strike to the earth surface. The earth electrode system shall consist of: (a) Single ground electrode, at each down - conductor (b) Multiple ground electrode (c) Concrete - encased electrode (d) Grow ring electrode Radials or any combination of the above. The specification describes the dimensions and size for earth electrodes as well as the test requirements value of the materials. A grounding electrode system that provides a single point of zero ground reference and a single point for system interconnection shall be installed.

3.4 Earth-Electrode with respect to corrosion: German specification DIN VDE0151: 1986 - 06 provide, information on how to avoid or reduce the risk of corrosion to earth electrode and with earth electrode of other systems installed. It also provides information to assist in making the correct choice of earth electrode materials and about the special anticorrosion measures [3]

3.5 Bonding specification. Bonding of metallic bodies and lightning protection ground system is required to ensure that voltage potentials produced by lightning currents are near - equal throughout the structure and no potential differences exist that would be sufficient to produce a side flash inside or on the surface of the protected structures. Requirement for bonding shall comply with NFPA. Method of Bonding may include the chemical, compression or thermal connection. All the metal bodies shall be bonded within six feet of lightning protection components. If NFPA 780 bonding calculation allows a greater distance, then use that distance. All metal masses that are integrated into the structure of the building, like steel doors steel reinforcing bars, utilities and communication system, shall be bonded to the nearest structure member of lightning protection system component that has all the parts completely bonded to the earth electrode system. The lightning protection 
system should be as short and as direct as reasonably achievable. The lightning protection system shall not be painted or coated. Bond resistances should be less than $\mathbf{1} \Omega$ for effective result unless approved by the AHJ.

3.6 Surge suppression standard: Surge suppression for incoming conductors shall be provided in accordance with NFPA780 as part of all power, communication security, data processing and control conductors that enter or leave a facility. The surge protection shall be located between the respective conductor and the structure ground as close as possible to the point where the conductor enters the lightning protection system zone of the structure.

3.7 Side flash protection: To prevent harmful effect by either the direct or the indirect effects of side flash, protection should be provided for equipment and personnel within the structure. Protection against harmful effect of side flash is achieved by separating the component and equipment from the lightning protection system. Side flash protection for all structures with lightning protection system shall be determined in accordance to NEPA 780.

\subsection{Maintenance Considerations}

All installed lightning protection systems shall be accessible for testing, maintenance and inspection. All lightning protection components shall be visible to facilitate future maintenance project, file containing layout drawings and lightning design documentations should be passed to client upon project completion. The lightning protection system should be certified and or inspected by a consultant in accordance with lightning protection inspection LPI 177 standard of inspection guide for certified systems. Monthly periodic visual inspections shall be performed to verify the followings: there are no lose connections that might result in highresistance connections, no corrosions, vibration, or substandard air termination, all down conductors and grounding electrode are intact and all conductors and system components are tightened securely to their mounting surface.

3.9 Testing Procedure: According to testing standards LPI 175; the following test shall be performed on the lightning protection systems.

- Perform continuity test on a representative sample of concealed building lightning protection component

- Perform a ground resistance test of the grounding electrode system and any individual electrodes that are accessible or visible to test

- Perform fall of potential ground (three point) test at each test point

- Use visible down conductors at building exterior as necessary

- Use of a clamp on resistance meter shall be approved by the AHJ prior to use

- Perform continuity testing to determine if suitable equipotent has been established for any new services (utility, communication, fire protection, power, CCTV, etc) or construction that has been added to the structure since the last inspection

3.10 Risk assessment required for lightning protection system: Lightning protection expert should carry out detailed inputs to risk assessment in accordance to NFPA 780 for structures and facilities. The choice of whether the simplified or detail assessment shall be basic or complex will depend on the information needs during any risk assessment.

\section{Control Measures that relate to Lightning Protection in Building Structure.}

It is very important to protect building structures against lightning and its effect, as there is no equipment or device able to change the natural weather phenomena in order to prevent lightning discharges [6]. One of the control measures to be put in place in protecting building against lightning discharges is to ensure that correctly designed air termination system is used in the building. The function of this is to capture the lightning discharge current and dissipate it harmlessly to earth via the down conductor and earth termination system. The air termination components should be installed on corners, exposed points and edges of the building structure.

Also, the quality of earth termination system should not be compromised. The equipment should be well- earthed. The earth termination system is very important for the dispersion of lightning current safely and effectively into the ground [7]. A good earth connection should possess low electrical resistance between the electrode and the earth and also good corrosion resistance [8].

The general principle, according to [7] is that the equipment that needs to be protected must be located in the Lightning Protection Zone whose electromagnetic characteristics are compatible with the equipment's stress withstand or immunity capability. All the electronic equipment in the building should be protected against Lightning Electromagnetic pulse (LEMP) by using relevant surge protection measures. 


\section{Lightning Protection as applied to building structures in a University in Nigeria.}

This University is Covenant University Ota, Nigeria, just over ten years old and is a growing university, where facilities and infrastructures are expanding rapidly - faculty buildings, laboratories, workshops, recreation centers, student hostels, staff quarters etc., even right now, many other buildings are under construction.

However, since the inception, the university had experienced at least two major lightning strikes that caused property damage but no life was lost or injured.

Even though some of the buildings have installed in them lighting protection systems, the most recent one that occurred in October, 2013, caused extensive damage to the telecommunication and data network equipment installed in the building.

This incident was investigated to determine the immediate and remote causes of the failure of the lightning protection equipments that were installed at that particular building. The investigation revealed that the continuity between the air terminal equipment at the top of the building and earth terminal at the ground was broken; and this was a major cause of failure. This should have been detected if the regular maintenance of the lightning protection systems had been carried out.

Though, lightning induced equipment damage is not as frequent as it is in some parts of the Country, lightning induced outages is rampant in the University. For this reason, lightning protection and safety scheme are given very high pirority in the University. Our research group is currently carrying out a research to determine the effectiveness of the grounding installation of each of the buildings within the university campus as well as the effectiveness of the air terminals available in Nigeria market in comparism to international specification. This exercise will also determine the resistivity of the soil at various depths to ensure that the earth terminal equipment is installed according to international standard.

Properly grounded electrical installations must achieve an equipotential level between all the associated grounding conductors and the surrounding earth. Failure of the grounding installation could pose serious electrical fire threat and could also render the lightning protection installations systems ineffective. This research will ensure that all our installed LPS in the entire campus are in line with internationally accepted specifications. We are presently conducting a research in collaboration with the Nigerian Metrological Department of the Federal Ministry of Aviation to determine the frequency of occurrence of lightning storm in South West region of Nigeria as well as detect or predict when lightning is expected to occur especially during the rainy season.This will enable the Government to send warning and alerts to residents both in cities and rural areas on lightning storms that may cause extensive damage to properties and possible loss of life. Another group is also researching into the types of structures/building materials that will be suitable in tropical regions to withstand the stress generated by lightning storms and strikes.

\section{Education and Enlightment}

Finally, we have also identified lack of awareness on the part of most occupants of these structures in respect of lightning protection schemes in most African countries. Most of the lightning incidents that resulted in death are not reported since they are often regarded as an act of "the god of thunder". We are now embarking on promotion of lightning protection education, awareness and safety to the Lightning Protection Installation Contractors and builders of structure to pay serious attention to effective and proper lightning protections of their structures and equipment within and around the structures. This will help to ensure the best possible quality in lightning protection materials and installation techniques.

\section{Conclusion:}

The paper did a review of lightning protection standards that have been developed and till date with particular reference to building in Nigeria. It covers the essential requirements for good protection against lightning fields with reference to buildings and structures in parts of Nigeria.

Finally the paper explained the efforts being made by researchers of Covenant University to promote lightning protection system through educating stage holders in building industries as well as the use of proven internationally accepted air terminations.

\section{References}

[1] National Fire Protection Association, NFPA 780, Standard for the Installation Protection System.

[2] Michael L. Henshan "Protection against Lightning, A UK guide to the practical application of BS EN 62305" British Standards, 2007.

[3] Lightning Protection Guide 45. German Standard DIN 0151: 1986-06. Available at www.dehn.de

[4] Lightning Protection Institute (LPI); LPI 175, Standard of practice for the design-installation-inspection of lightning protection systems.

[5] LPI 177, Standard of Inspection Guide for certified Systems.

[6] Protection against Lightning. A Uk guide to the practical application of BSEN 62305.

[7] Guide to BSEN/IEC 62305 available online at www.furse.com

[8] Kim Loehr “The Importance of Standards for lightning protection” PM Engineer Magazine, December 2007. 